\title{
Research on Risk Measurement in Financial Market Based on GARCH-VaR and FHS - - An Example of Chinese Bond Market
}

\author{
Shaozhen Chen ${ }^{1}$, Bangqian Zhang ${ }^{1} \&$ Jinjin Deng ${ }^{1}$ \\ ${ }^{1}$ Finance Department of International Business School, Jinan University, Qianshan Road 206\#, Zhuhai City, Guangdong \\ Province, China \\ Correspondence: Jinjin Deng, Finance Department of International Business School, Jinan University, Qianshan Road \\ 206\#, Zhuhai City, Guangdong Province, Post No. 519070, China.
}

Received: May 27, 2018

doi:10.11114/aef.v5i4.3307
Accepted: June 19, 2018 Available online: June 22, 2018

URL: https://doi.org/10.11114/aef.v5i4.3307

\begin{abstract}
Accurately measuring the risk of bond market is very important for improving the risk management level of bond market and maintaining the stability of the financial system. Taking ChinaBond New Composite Wealth (gross) Index as the research object, this paper selects the closing price from January 1, 2002 to March 30, 2018, establishes the GARCH, EGARCH and GJR-GARCH model based on normal distribution and distribution, and finds out the volatility aggregation and the leverage effect of the bond market. Then, this paper use two methods to measure the risk of the bond market: first, we estimate the value at risk $(\mathrm{VaR})$ of the bond market by the parameter method, using conditional variance estimated by the GARCH models, and we carry out backtesting analysis and the Kupiec failure rate test on measurement accuracy of VaR. The results show that $t$ distribution hypothesis and elimination of autocorrelation of the yield rate can improve the accuracy and robustness of the estimation of the VaR; second, we simulate the future revenue path of the bond market and compare it with the actual loss, using Filtered Historical Simulation (FHS) based on Bootstrap method. The results show that the bond market has leverage effect. The maximum possible loss under extreme conditions can be far greater than the maximum possible revenue. But the estimated VaR under 95\% confidence level can predict future risks very well. Finally, according to the conclusion, this paper puts forward some suggestions for regulators and investors from the perspective of risk management.
\end{abstract}

Keywords: volatility, leverage, GARCH models, VaR, FHS

\section{Introduction}

The Asian financial crisis that broke out in 1997 gives us a lesson that the development of multi-level capital markets, especially the bond market, is of great significance to the stability and prosperity of finance and economy in a region and even a country. The development of the bond market will help expand the financing channels, establish indirect control mechanisms, promote the reform of interest rate liberalization and then increase the efficiency of the allocation of financial resources. Therefore, how to ensure the healthy development of the bond market and let the bond market risk buffer play their full role, or how to accurately measure the risk of the bond market and improve the level of risk management are of great practical significance.

Since Chinese government resumed issuing national debt in 1981, the bond market has so far achieved rapid development. Regulatory system has been gradually improved; bond types have become increasingly diverse; a unified layered market system including three submarkets, which are inter-bank bond market, exchange bond market, and commercial bank over-the-counter market has gradually emerged. The bond market plays an important role in the implementation of the macroeconomic regulation carrier while playing a financing function. The regulatory authorities regulate the money supply through open market operations such as cash coupon trading and repurchase in the bond market to achieve monetary policy goals; they can also achieve financial policy goals through the scientific arrangement of the size, timing, and term structure of government bond issuance; they can guide the flow of bond financing as well by rationally adjusting the structure of bond issuers to optimize the industrial structure and achieve the purpose of healthy industrial development.

At the end of 2017, the stock size of China's bonds was 74.66 trillion yuan, and the bond market issued a total of 40.8 trillion yuan in various bonds. Among them, the scale of bonds issued by the inter-bank bond market reached 36.8 
trillion; the issuance of government bonds reached 3.9 trillion yuan; the issuance of local government bonds reached 4.4 trillion yuan; the issuance of financial bonds reached 5 trillion yuan; government-sponsored institutional bond issuance reached 286 billion yuan; asset-backed securities reached 1.5 trillion yuan; interbank certificates issued amounted to 20.2 trillion yuan; corporate credit bonds issued amounted to 5.5 trillion yuan. It can be seen that the bond market has become an important place for direct financing in China. It is not only an important part of the financial market, but also an important platform for national macroeconomic regulation and control. Bond market plays an increasingly important role in the stable development of the national economy.

However, compared with the developed bond market, China's bond market is still a developing market with a short development period, a weak system, and a structure that needs improvement. The lack of risk management tools and the deficiencies in risk control mechanisms have aggravated the risk accumulation in the bond market. According to Wind statistics, there have been 140 bond defaults since 2014, involving a balance of 79.754 billion yuan. Among them, 35 new default bonds were issued in 2017, involving a balance of 28.060 billion yuan, which was still a great amount of money despite a $27.58 \%$ year-on-year decrease. In response, China's supervisory authorities have successively introduced a number of policy measures since 2017 to strengthen pre-, intra- and ex post management of various bond risks. However, authorities not only need to formulate various policies and regulations on the micro level, but also needs to understand the overall market risk situation on a macro level in order to manage risk of the bond market. The futures crisis in the late 1990s and the financial crisis that broke out in 2008 all underscore the importance of overall financial risk control. This also puts forward higher requirements for financial risk measurement. How to accurately measure risks and improve risk management levels to ensure the healthy development of the bond market and give full play to the role of the risk buffer in the bond market is a major issue that we urgently need to resolve.

\section{Literature Review}

In the study of risk in the bond market, foreign scholars started earlier. The research content mainly includes three aspects: first, the study of bond liquidity and volatility risk; second, the factors that contribute to bond premium risk; third, the influencing factors on the pricing of corporate bonds. Chordia et al. (2003) studied the mechanism of interaction between liquidity, trading activity, yield, and volatility between the stock market and the bond market. The results showed that the stock market and bond markets had similar liquidity patterns. The interaction between volatility and liquidity did exist, that is, there were the same influencing factors that affected each other systematically. John and Monika (2005) studied the characteristics of the time variation of expected excess bond yields, and conducted a regression analysis of the one-year excess return of the initial forward rate. A single tent-shaped long-term interest rate linear combination was used to predict the excess returns of 1- to 5-year bonds, and the regression results showed that $\mathrm{R}^{2}$ was as high as 0.44 . Heinke (2006) studied the relationship between bond credit risk premiums, volatility, and credit ratings. He used panel data to compare credit spreads before and after changes in credit ratings. Using t-test to study how volatility changes depend on the credit rating. Heinke drew the conclusion that there is an inverse relationship between ratings and volatility. Ludger et al. (2009) empirically studied the risk premiums of the European Central Government and the sub-national governments of Germany, Spain and Canada and found that the central government's risk premium has a positive response to debt and deficits. Jürgen et al. (2011) studied the spreads of government bonds denominated in US dollars and euros relative to benchmark bonds in the United States and Germany before and after the 2008 financial crisis. The empirical evidence showed that after the crisis, the spread of non-benchmark bonds rose sharply due to the increase in the degree of general risk aversion. German bonds had acquired similar safe-haven investment status as the United States. Darbha and Dufour (2014) studied the relationship between the risk of default in a country and the insufficiency of liquidity in issuing bonds. Empirical evidence showed that the non-liquidity of bonds depended on the level of market development in the country. The sovereign debt default decision made the liquidity of the subordinate bond market insufficient through debt transfer channels. Liang et al. (2016), under the framework of the structural model, constructed a corporate bond indiscriminate pricing model for credit-level migration by conditionally applying credit rating migration boundaries. Using dynamic programming theory, Liang et al. analyzed the impact of model parameters on indiscriminate pricing. Pan (2016) built a corporate bond pricing model based on risk hedging by introducing stochastic recovery rate and default intensity, and found that intensity and recovery parameters were important factors affecting bond credit spreads. Claudia et al. (2017) used the DCC-GARCH model to analyze the correlation between the credit spreads of the U.S. and Canadian corporate bond markets. The empirical evidence showed that the correlation between the two markets during the normal period was weak, but the correlation increased suddenly during the crisis. Thomas (2018) studied the characteristics of the time variation of government bond yields based on the global asset-return pricing model. Empirical evidence showed that $40 \%$ to $70 \%$ of the time variation in US dollar-denominated bond income was related to the global bond market and exchange rate risk.

China's researches on the risk of bond market mainly focus on the theoretical discussion of market management mechanism. The empirical research content is mainly focused on the credit risk of municipal bonds and corporate bonds. 
A few studies are focused on liquidity risks. Ba Shusong (2000) described the impact of the development of the bond market on the country's monetary policy and pointed out how to manage the interest rate risk of the bond market from the perspective of interest rate risk. Li Yan (2003) clarified how to correctly understand the credit risk of corporate bonds, and suggested that the construction of corporate bond market requires information disclosure system and believed that the government must strengthen the supervision of information disclosure. Liu Shangxi and Zhao Xiaojing (2005) believed that there are public risks and fiscal risks in the issuance of municipal revenue bonds. The ways to prevent risks were to improve the relevant laws and regulations, design a market framework for municipal revenue bonds, and reform the government investment system. Yang Qinyan (2007) used the KMV model to measure the credit risk of municipal bonds in Hangzhou and Ningbo, two economically more developed cities, and then proposed policy recommendations based on empirical results from the perspective of market institutional norms. Zhang Rui (2010) established an error correction model to study the impact of different influencing factors on the liquidity of the bond market. Empirical evidence showed that domestic money supply was the main driving force of the current bond market liquidity, and that international capital market risk had a negative impact on bond market liquidity. The impact of the major international exchange rate fluctuations and international capital costs would affect the bond market liquidity in a long-term way through various channels. Zhang Yuyan and Lu Jin (2012) pointed out that self-discipline management was of great significance in the bond market. Promoting self-discipline management would contribute to the development and innovation of the Chinese bond market. Hou Xianping (2016) conducted a multidimensional analysis of the bond market risk based on the GAHCH family model and VaR method. The application scope and accuracy of various models were compared and studied through rigorous posterior analysis, and then the application values of different typical facts in risk management were analyzed. Zong Jun (2017) pointed out the current general risks and other structural impacts of China's bond market, and proposed a methodology for macro-management of bond market risks, and a risk management toolbox to be adopted. From the perspective of credit risk, Sun Jifeng (2017) used the DS model and the KMV model to study the bond defaults of listed companies in China. The empirical results showed that when the issuer's credit rating was at or above level A, the credit status of the issuer was better and the default distance was bigger. However, when the bond issuer's credit status was below level A, the better the credit status of the issuer, the greater the default distance. Song Meiyi and Hu Yuji (2018) established a threshold model to capture the non-linear effects of market interest rates on the credit risk of the bond market. The empirical results showed that long-term interest rates had a positive impact on credit risk as a whole, and short-term interest rates had an opposite effect on credit risk, depending on the degree of currency liquidity.

Judging from the focus of research, when studying the risks of the bond market both at home and abroad, more micro-perspectives are taken to study the credit risk of municipal bonds and corporate bonds. There is little research on the overall risk measurement of the bond market. However, in the stock market, research on financial market risk measurement is mature. The most widely used financial risk quantitative measure is the loss distribution metric method, and the most common one is the VaR and ES measure technology. The concept of VaR was proposed by the Bank for International Settlements in 1993. The calculation methods include parameter method, historical simulation method and semi-parametric extreme value theory. The parametric method generally assumes that the rate of return belongs to the position-scale distribution family, that is, the rate of return can be represented by the mean, the standard deviation (also called the volatility) of the yield, and the random error. Because the average yield rate has little effect on VaR, researchers mainly focus on the volatility and error distribution. The volatility estimation is generally based on GARCH model and SV model. The error distribution assumes that the residual obeys Gaussian distribution, t distribution, GED distribution and so on. Applications in this area include Siu et al. (2000), Tang and Shieh (2006), Wua and Shiehb (2007). The historical simulation method is considered to be the most convenient method for estimating VaR. It is not necessary to make assumptions about the entire distribution of returns, and the sample quantile of the historical income distribution is used as an estimate of VaR. Barone et al. (1998) showed that the historical simulation method had good prediction performance. In response to the limitations of the historical simulation method, Barone et al. (2002) introduced the Filtered Historical Simulation (FHS) method. The significant advantage is reflected in the expansion of the scope of historical scenarios through a weighting factor, and the improvement of the tail portion of the revenue. Therefore, it has received great attention in the field of risk management. Adesi et al. (2001), Pritsker (2006), and Sukcharoensin (2010) used the FHS technique to measure VaR and achieved good results. The semi-parametric extreme value theory (EVT) is the study of modeling and statistical analysis of extreme variability of random variables that rarely occur, but that have a significant impact once they occur. At present, the POT model based on generalized Pareto distribution is the mainstream of extreme value theory. Bali (2007) found that EVT method using the Box-Cox generalized extreme value distribution can more accurately reflect the extreme risks of financial institutions. Bhattacharyya et al. (2008) combined the GARCH model and the EVT model to construct a VaR measurement model for the dynamic volatility and nonnormality of stock return, and concluded that the dynamic VaR model is the best model for measuring VaR. 
In summary, most scholars at home and abroad studied the bond market from the perspectives of credit risk, liquidity risk and market management, but seldom measured the overall risk of the bond market from the perspective of financial measurement. Therefore, this paper will use the multi-dimensional volatility GARCH model for the bond market using the data of China Bond New Comprehensive Wealth (Gross Value) Index from January 1, 2002 to March 30, 2018, and measure the dynamic risk value of the market (VaR). Then this paper will perform back test analysis and Kupiec failure rate test on different GARCH-VaR to obtain a robust volatility model. Finally, based on a robust GARCH model, this paper will use FHS to simulate the future yield path and obtain VaR after Backtest analysis. Based on the above empirical results, this article can provide market regulators and investors with relevant risk management recommendations.

\section{Theoretical Model}

\subsection{GARCH Model}

Volatility agglomeration is a salient feature of financial time series, especially the return rate series. When characterizing volatility accumulation, the most commonly used models are the GARCH model and the SV model. This article uses the GARCH model to empirically analyze the bond market index, and its methods briefly are as follows.

\subsubsection{GARCH (p, q)}

The GARCH model is an extension of the ARCH model, proposed by T. Bolerslev in 1986, and is particularly applicable to the analysis and prediction of volatility. The model equation for GARCH $(p, q)$ is:

$$
\left\{\begin{array}{l}
y=x_{t}^{\prime} \varphi+u_{t}, u_{t} \sim N\left(0, \sigma_{t}^{2}\right) \\
\sigma_{t}^{2}=\omega+\sum_{i=1}^{p} \alpha_{i} u_{t-i}^{2}+\sum_{j=1}^{q} \beta_{j} \sigma_{t-j}^{2}
\end{array}\right.
$$

Where $\omega>0, \alpha_{i} \geq 0, \beta_{i} \geq 0, \sum_{i=1}^{p} \alpha_{i}+\sum_{j=1}^{q} \beta_{i}<1$

\subsection{2 $\operatorname{EGARCH}(\mathrm{p}, \mathrm{q})$}

Nelson (1991) proposed the EGARCH model, which is a model that can reflect the asymmetry of financial market volatility. The EGARCH (p, q) model equation is:

$$
\left\{\begin{array}{l}
y=x_{t}^{\prime} \varphi+u_{t}, u_{t} \sim N\left(0, \sigma_{t}^{2}\right) \\
\ln \sigma_{t}^{2}=\omega+\sum_{k=1}^{r} \theta_{k} \frac{u_{t-k}}{\sigma_{t-k}}+\sum_{i=1}^{p} \alpha_{i} \frac{\left|u_{t-i}\right|}{\sigma_{t-i}}+\sum_{j=1}^{q} \beta_{j} \ln \sigma_{t-j}^{2}
\end{array}\right.
$$

Where $\theta \neq 0$ means that the impact of external shocks on fluctuations is asymmetrical; where $\theta<0$ means that the influence of negative shock on the price fluctuation of financial products is greater than the impact of positive shock, that is "Leverage effect".

\subsubsection{GJR-GARCH (p, q)}

GJR-GARCH was proposed by Glosten, Jagannathan and Runkle in 1993. Like EGARCH, it contains a leverage term to characterize asymmetric fluctuations in financial markets. Its equation can be expressed as:

$$
\left\{\begin{array}{l}
y_{t}=x_{t}^{\prime} \varphi+u_{t}, u_{t} \sim N\left(0, \sigma_{t}^{2}\right) \\
\sigma_{t}^{2}=\omega+\sum_{i=1}^{p} \alpha_{i} u_{t-i}^{2}+\sum_{j=1}^{q} \beta_{j} \sigma_{j-1}^{2}+\sum_{j=1}^{q} \gamma_{j} D_{t-j} \sigma_{t-j}^{2}
\end{array}\right.
$$

Where $D_{t-1}$ is a dummy variable, and meet the following conditions.

$$
\left\{\begin{array}{l}
D_{t-j}=0, u_{t-i}>0 \\
D_{t-j}=1, u_{t-i}<0
\end{array}\right.
$$

If $\gamma_{t}>0$, then negative shocks have greater impact on conditional variance than positive shocks, suggesting a "leveraging effect" in the market. 


\subsection{VaR Measure Based on GARCH Model}

VaR (Value at Risk) is interpreted literally as "risk value". Its meaning refers to the maximum possible loss of the value of a certain financial asset or portfolio within a certain period of time at a certain probability level (confidence). When $\mathrm{Q}$ stands for loss and $\mathrm{p}$ stands for probability level, VaR within period $\mathrm{t}$ can be expressed as:

$$
\operatorname{Pr}[Q<-\operatorname{VaR}(p)]=p
$$

At the assumption of continuous compounding, with day as a measurement of time, the derivation of VaR is as follows:

First define the log yield

$$
Y_{t}=\log P_{t}-\log P_{t-1}
$$

And then we get the following expression

$$
\begin{aligned}
p & =\operatorname{Pr}\left(P_{t}-P_{t-1} \leq-\operatorname{VaR}(p)\right) \\
& =\operatorname{Pr}\left(P_{t-1}\left(e^{Y_{t}}-1\right) \leq-\operatorname{VaR}(p)\right) \\
& =\operatorname{Pr}\left(\frac{Y_{t}}{\sigma} \leq \log \left(-\frac{\operatorname{VaR}(p)}{P_{t+1}}+1\right) \frac{1}{\sigma}\right)
\end{aligned}
$$

Because $-\operatorname{VaR}(p) / P_{t-1} \leq 1$, representing $\left(Y_{t} / \sigma\right)$ with $F_{y}(\cdot)$, making $\gamma(p)$ equals $F_{y}^{-1}(p)$, we can list a new equation as below.

$$
\operatorname{VaR}(p)=-\left(\exp \left(F_{y}^{-1}(p) \sigma\right)-1\right) P_{t-1}
$$

For a small $F_{y}^{-1}(p) \sigma$, The VaR of a unit asset can be approximated as:

$$
\operatorname{VaR}(p) \approx-\sigma \gamma(p) P_{t-1}
$$

In this paper, when estimating VaR, we use the GARCH family model of Section 3.1 to calculate the conditional standard deviation. Substituting the above formula, we can get the dynamic VaR based on GARCH.

\subsection{Kupiec Failure Rate Test}

The accuracy test of the VaR model refers to the degree of coverage of the actual losses by the measurement results of the VaR model. Therefore, examining the probability that actual losses exceed VaR is the most direct method of accuracy testing. This paper selects the Kupiec likelihood ratio test as a backtesting model for further analysis.

The idea of the failure frequency test proposed by Kupiec is to assume that the VaR estimation has a time independence, and then we record the actual daily loss exceeding the VaR estimate as failure, and record the actual loss below the VaR estimate as successful. If it is assumed that each event has time independence, the binomial result of the failed observation represents a series of independent Bernoulli tests.

Assumed actual days of inspection to be $T$ and the Number of days failed to be $N$, then we can get probability of failure as $p=N / T$. If the selected confidence level is $q$, and the probability of failure is expected to be $P^{*}=1-q$, then we can get the null hypothesis as $p=p^{*}$.

Kupiec proposed that the most appropriate test for the null hypothesis $p=p^{*}$ is the likelihood ratio test:

$$
L R=-2 \ln \left[1-p^{*}{ }^{T-N} p^{*}\right]+2 \ln \left[\left(1-\frac{N}{T}\right)^{T-N}\left(\frac{N}{T}\right)^{N}\right]
$$

Statistics $L R$ obeys the chi-square distribution with a degree of freedom of 1 . At a level of significance of $5 \%$, the critical value of Chi-square statistics is 3.84 . Therefore, when $L R>3.84$,we can reject the null hypothesis and the model as well. In general, the smaller the number of failures, the smaller the LR, that is, the more accurate the model and the higher the credibility. However, a small number of failures means that the model is too conservative, which can sometimes cause the LR to be too large and reject the null hypothesis.

\subsection{Bootstrap Resampling}

The Bootstrap method is a simulated sampling statistical inference method. It is based on the original data and can be 
used to study the distribution characteristics of a statistic for a group of data. It is particularly applicable to problems such as interval estimation and hypothesis testing that are difficult to derive by using conventional methods. The basic idea is to construct an estimated confidence interval with the help of multiple sampling of partial samples when all samples are unknown. The algorithm flow is as follows:

Target: For a sample $x_{1}, x_{2}, \ldots, x_{n}$, the parameters of its overall probability distribution $\theta$ such as mean, median is unknown. Now we want to take advantage of this limited sample to get an estimate of $\hat{\theta}$.

Stepl Select the number of resampling $i$;

Step2 Retrieving $\mathrm{N}$ times from the sample $x_{1}, x_{2}, \ldots, x_{n} \quad N<i$;

Step3 Repeat Step2 with $i$ times, and calculate $\hat{\theta}$ for each sample;

Step4 Use the resulting data $\hat{\theta}_{1}, \hat{\theta}_{2}, \ldots, \hat{\theta}_{i}$ as a sample, and we can get the value when its quantile is $\alpha$; The percentage position can be calculated according to Equation $1 \alpha / 2 \times 100 \%$ and Equation $2(1-\alpha / 2) \times 100 \%$. At the same time the confidence interval $\left[\theta_{\alpha / 2}, \theta_{(1-\alpha / 2)}\right]$ of the parameter $\theta$ with significance level $\alpha$ can be further obtained.

\subsection{Filter History Simulation}

Filtered Historical Simulation (FHS) is a new nonparametric historical simulation method proposed by Barone-Adesi G and Giannopoulos K. As the traditional historical simulation method assumes that the future changes of market factors are completely consistent with historical changes, it cannot handle the extreme situations of the market well. Under extreme circumstances, it will underestimate market risks. The advantage of the FHS is that it can simulate extreme events in a systematic way, so that it can well characterize the tail of the income distribution and better measure market risks. Take AR(1)-GARCH(1,1) as an example, the FHS implementation steps are as follows:

Stepl Standardized processing: Standardize the residual error sequence (sample) obtained by the GARCH model to obtain the residual sequence that obeys i.i.d.

$$
e_{t}=\frac{{ }_{t}}{\sqrt{\sigma_{t}}}
$$

Step2 Initial value selection: Assume that the current time is t, and then draw samples of return rate $r_{t}$, standardized residual $e_{t}$ and Volatility $\sigma_{t}$ at time trom Stepl, as a random error in the simulation of the first day's return rate series. After that we can get The return rate and volatility at $\mathrm{t}+1$,

$$
\begin{aligned}
& \hat{r}_{t+1}=\rho r_{t}+\varepsilon_{t} \\
& \hat{\sigma}_{t+1}^{2}=\omega+\alpha \varepsilon_{t}^{2}+\beta \sigma_{t}^{2}
\end{aligned}
$$

Step3 Iterative simulation: Use Bootstrap method to draw the normalized residual from Step1 as a random error of the return rate sequence at the time of $t+p$ in the future, and also we can obtain the asset return rate and volatility at $t+p+1$. Repeat Step3 to get the asset's return rate sequence:

$$
\begin{aligned}
& \hat{\varepsilon}_{t+p}=e_{t+p} \sqrt{\hat{\sigma}_{t+p}} \\
& \hat{r}_{t+p+1}=\rho \hat{r}_{t+p}+\hat{\varepsilon}_{t+p} \\
& \hat{\sigma}_{t+p+1}^{2}=\omega+\alpha \hat{\varepsilon}_{t+p}^{2}+\beta \hat{\sigma}_{t+p}^{2}
\end{aligned}
$$

After several simulations of the bond index, we can get the cumulative returns for the next $\mathrm{N}$ days. According to the cumulative distribution function (CDF), we can obtain the VaR at a certain confidence level from the quantile.

\section{Empirical Research}

\subsection{Data Selection and Description}

ChinaBond New Composite Index is issued by China Central Depository \& Clearing Co., Ltd. (CCDC) to reflect the overall price trend and revenue of the bond market in China. Compared with other indexes, ChinaBond New Composite Index covers a wider range and reflects a more comprehensive trend of price movements in China's bond market. Therefore, based on the discussion above, this paper takes ChinaBond New Composite Wealth (gross) Index as the 
research object, and selects the data from January 1, 2002 to March 30, 2018 as the sample, with a total of 4065 data. The sample covers three states of the bond market including the bull market, bear market and shock market. Therefore, the statistics derived from the sample can well describe the normal situation and extreme situation of the market. The data in this paper comes from the Wind database.

\subsection{Descriptive Statistics and Stability Test}

\subsubsection{Descriptive Statistics}

This paper denotes the daily yield rate of the bond market by $r_{t}$, which is defined as follows:

$$
r_{t}=100 \times \ln \frac{P_{t}}{P_{t-1}}
$$

in which, $P_{t}$ stands for the daily closing price of the bond index, $t=1,2, \ldots, N$. The logarithmic yield is multiplied by 100; we do so in order to reduce the estimated error. With the help of MATLAB, we can get the descriptive statistical results and the yield rate time series diagrams of the bond market, as shown in Table 1 and figure 1. Table 1. Descriptive statistics of the yield rate of ChinaBond New Composite Wealth (gross) Index

\begin{tabular}{ccccccccc}
\hline Mean & Median & Max & Min & S.D. & Skewness & Kurtosis & J-B & Prob (J-B) \\
\hline 0.01402 & 0.01432 & 0.7735 & -0.8424 & 0.1152 & -0.0333 & 11.96 & 13625.06 & 0.0000 \\
\hline
\end{tabular}

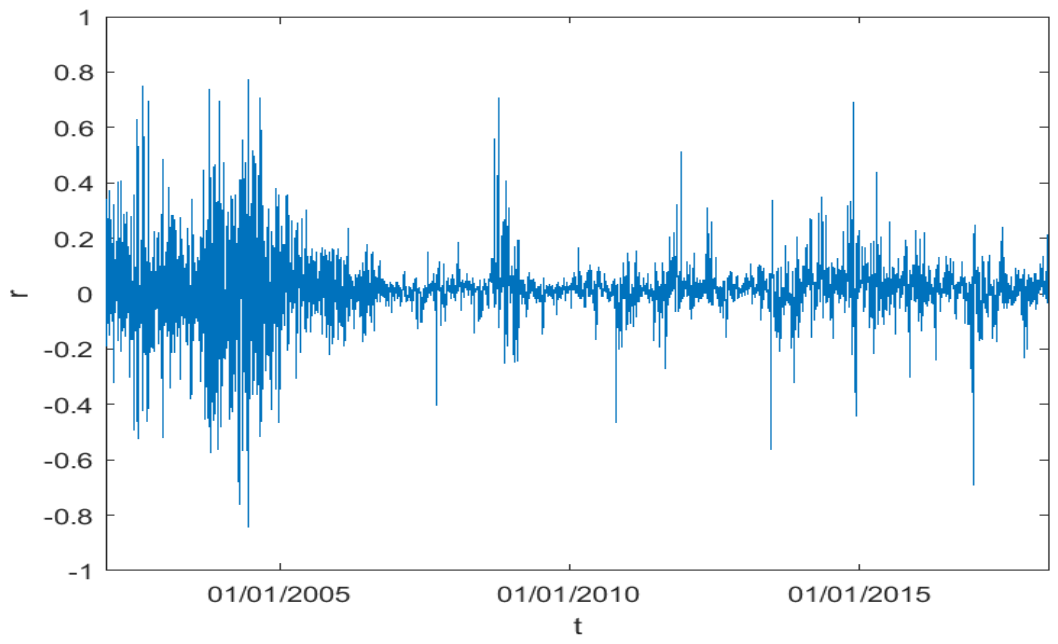

Figure 1. Yield rate time series diagrams of ChinaBond New Composite Wealth (gross) Index

From table 1, we can see that the yield rate of ChinaBond New Composite Index is rejected by the normal distribution hypothesis, and shows a significant characteristic of fat tails with skewness, which can be seen more intuitively by drawing the QQ diagram as shown in Figure 2.

From Figure 1, it is clear that, from 2004 to 2005, from 2008 to 2009, in the second half of 2013 and in 2015, the volatility of the yield rate of ChinaBond New Composite Index tends to enlarge obviously and shows the effect of volatility aggregation. In retrospect, it is known that in 2004 the central bank led the central interest rate down, turning the bear market into bull market; in 2008, the bond market was hit by the subprime crisis, bear market came again; in 2013, the central bank tightened up money supply, the market faced money shortage; in 2015, after the stock market's prosperity and following huge fluctuation, the currency poured into the bond market. In a word, the yield rate of ChinaBond New Composite Index can well reflect the volatility of the market and depict market risks. 


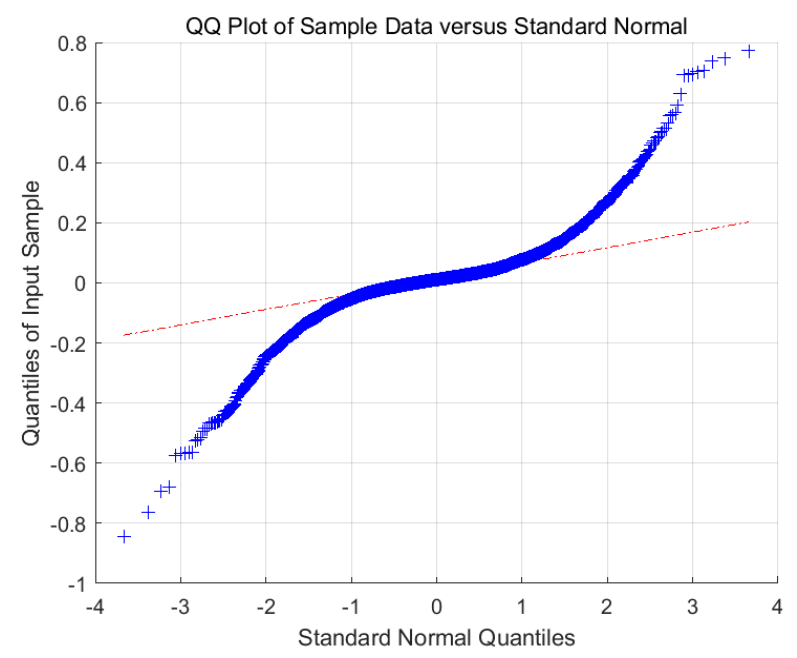

Figure 2. QQ diagram of ChinaBond New Composite Wealth (gross) Index

\subsubsection{Stability Test}

In order to avoid spurious regression, we need to test the stability of sequences. In this paper, we use ADF test to test the yield series of ChinaBond New Composite Wealth (gross) Index. The results are shown in Table 2.

Table 2. ADF test results of ChinaBond New Composite Wealth (gross) Index

\begin{tabular}{l|l|l}
\hline \multicolumn{2}{l|}{ Augmented Dickey-Fuller test statistic } & -12.1668 \\
\hline \multirow{2}{*}{$\begin{array}{l}\text { Test critical } \\
\text { values }\end{array}$} & $1 \%$ level & -3.4317 \\
\cline { 2 - 3 } & $5 \%$ level & -2.8621 \\
\cline { 2 - 3 } & $10 \%$ level & -2.5671 \\
\hline
\end{tabular}

\subsection{GARCH Model}

\subsubsection{Autocorrelation and Partial Correlation Test}

We carry out the autocorrelation and partial correlation test of the yield of ChinaBond New Composite Wealth (gross) Index. It can be seen from figure 3 that there is a certain autocorrelation and partial correlation in the yield sequence.
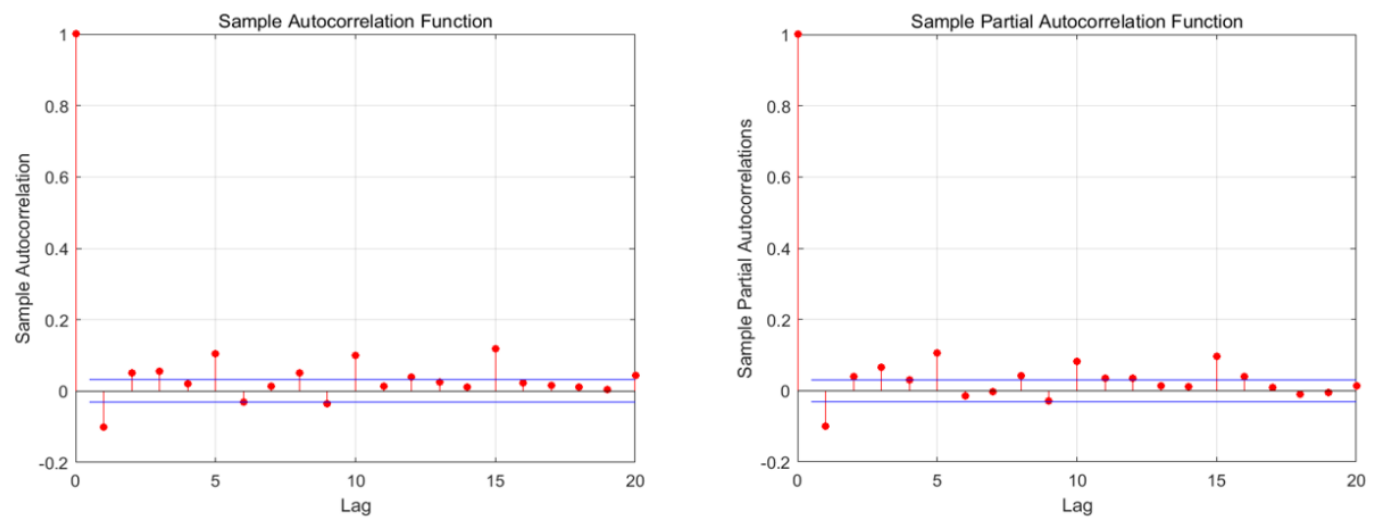

Figure 3. Autocorrelation and partial correlation test

\subsubsection{Mean Equation}

The stochastic volatility model of yield rate in financial time series is generally as follows:

$$
r_{t}=\mu_{t}+\varepsilon_{t}, \varepsilon_{t} \sim N\left(0, \sigma_{t}^{2}\right)
$$

in which, $\mu_{t}$ is conditional mean for yield, $\varepsilon_{t}$ is residual, $\sigma_{t}^{2}$ is conditional variance. Because the mean value of yield rate in financial time series is much smaller than its standard deviation (see Table 1), the conditional mean can be regarded as 0 . On the other hand, the estimation of the mean of yield rate has little influence on VaR, plus it was proved that AR (1) can well describe the conditional mean of yield. Therefore, this paper chooses the following two as the mean equation of GARCH: 


$$
\begin{aligned}
& r_{t}=\varepsilon_{t}, \varepsilon_{t} \sim N\left(0, \sigma_{t}^{2}\right) \\
& r_{t}=c+\rho r_{t-1}+\varepsilon_{t}, \varepsilon_{t} \sim N\left(0, \sigma_{t}^{2}\right)
\end{aligned}
$$

\subsubsection{Test of ARCH Effect}

We carry out ARCH-LM test on the residual sequence obtained from the mean equation. As shown in Table 3, under the significant level of 5\%, the LM test with the lag order of 1 rejects the null hypothesis, so the GARCH model can be established.

Table 3. Test of ARCH effect

\begin{tabular}{lllll}
\hline & Hypothesis & Probability & F-statistic & Critical Value \\
\hline Mean=0 & 1 & 0 & 449.8704 & 6.6349 \\
AR $(1)$ & 1 & 0 & 458.1801 & 6.6349 \\
\hline
\end{tabular}

Note. In the column Hypothesis, 1 indicates the rejection of null hypothesis and the existence of ARCH effect.

\subsubsection{Parameter Estimation}

Previous results show that the yield sequence of financial market not only has autocorrelation and volatility aggregation, but also has the characteristics of leverage effect and fat tails. Because GARCH $(1,1)$ model can well describe the market's volatility aggregation, this paper takes GARCH $(1,1)$ as the basic function. In order to determine more accurately whether the bond market has this feature, this paper uses the GJR $(1,1)$ model and the EGARCH $(1,1)$ model to verify it when leverage effect is taken into consideration. We assume that the yield residual is subordinate to $t$ distribution and compare it with the normal distribution hypothesis when taking the fat tails distribution in the yield sequence into consideration. The estimated results are shown in Table 4.

\begin{tabular}{|c|c|c|c|c|c|c|c|c|c|c|}
\hline Model & $c$ & $\rho$ & $\omega$ & $\alpha_{1}$ & $\beta_{1}$ & $\theta_{1}$ & $\gamma_{1}$ & $\begin{array}{l}\text { Log-likelih } \\
\text { ood }\end{array}$ & AIC & BIC \\
\hline GARCH $(1,1)-\mathrm{N}$ & - & - & $\begin{array}{c}0.0001537 \\
(32.05)\end{array}$ & $\begin{array}{l}0.1786 \\
(29.21)\end{array}$ & $\begin{array}{l}0.8214 \\
(198.1)\end{array}$ & - & - & 4498 & -8991 & -8972 \\
\hline $\operatorname{EGARCH}(1,1)-\mathrm{N}$ & - & - & $\begin{array}{l}-0.1945 \\
(-21.05)\end{array}$ & $\begin{array}{l}0.3874 \\
(39.52)\end{array}$ & $\begin{array}{l}0.9514 \\
(568.6)\end{array}$ & $\begin{array}{l}-0.07442 \\
(-12.97)\end{array}$ & - & 4477 & -8947 & -8922 \\
\hline GJR(1,1)-N & - & - & $\begin{array}{c}0.0001650 \\
(30.26)\end{array}$ & $\begin{array}{l}0.1507 \\
(21.46)\end{array}$ & $\begin{array}{l}0.8192 \\
(186.5)\end{array}$ & - & $\begin{array}{c}0.06010 \\
(6.533)\end{array}$ & 4506 & -9005 & -8980 \\
\hline $\begin{array}{l}\text { GARCH }(1,1)-\mathrm{t} \\
\mathrm{DoF}=4.7351\end{array}$ & - & - & $\begin{array}{c}0.0001032 \\
(6.112)\end{array}$ & $\begin{array}{l}0.2020 \\
(12.24)\end{array}$ & $\begin{array}{l}0.7979 \\
(66.22)\end{array}$ & & - & 4845 & -9681 & -9656 \\
\hline $\begin{array}{c}\mathrm{EGARCH}(1,1)-\mathrm{t} \\
\mathrm{DoF}=4.1423\end{array}$ & - & - & $\begin{array}{l}-0.1008 \\
(-5.432)\end{array}$ & $\begin{array}{l}0.3463 \\
(16.58)\end{array}$ & $\begin{array}{l}0.9793 \\
(272.6)\end{array}$ & $\begin{array}{c}-0.02359 \\
(-2.248)\end{array}$ & - & 4848 & -9686 & -9655 \\
\hline $\begin{array}{c}\mathrm{GJR}(1,1)-\mathrm{t} \\
\mathrm{DoF}=4.8045\end{array}$ & & & $\begin{array}{c}0.0001094 \\
(6.365)\end{array}$ & $\begin{array}{l}0.1868 \\
(10.56)\end{array}$ & $\begin{array}{l}0.7962 \\
(65.92)\end{array}$ & & $\frac{0.03375}{(1.610)}$ & 4846 & -9682 & -9650 \\
\hline $\begin{array}{c}\mathrm{AR}(1,1)-\mathrm{GARCH}( \\
1,1)-\mathrm{N}\end{array}$ & $\begin{array}{c}0.01128 \\
(13.25)\end{array}$ & $\begin{array}{l}0.2177 \\
(14.93)\end{array}$ & $\begin{array}{c}0.0001240 \\
(25.51)\end{array}$ & $\begin{array}{l}0.1767 \\
(30.28)\end{array}$ & $\begin{array}{l}0.8232 \\
(196.1)\end{array}$ & - & - & 4718 & -9426 & -9394 \\
\hline $\begin{array}{l}\operatorname{AR}(1,1)-E G A R C H \\
(1,1)-\mathrm{N}\end{array}$ & $\begin{array}{l}0.01224 \\
(17.25)\end{array}$ & $\begin{array}{l}0.2514 \\
(16.48)\end{array}$ & $\begin{array}{l}-0.1247 \\
(-13.82)\end{array}$ & $\begin{array}{l}0.3592 \\
(41.83)\end{array}$ & $\begin{array}{l}0.9685 \\
(575.8)\end{array}$ & $\begin{array}{l}-0.3228 \\
(-5.558)\end{array}$ & - & 4732 & -9453 & -9415 \\
\hline $\begin{array}{l}\operatorname{AR}(1,1)-\mathrm{GJR}(1,1)- \\
\mathrm{N}\end{array}$ & $\begin{array}{l}0.01088 \\
(11.28)\end{array}$ & $\begin{array}{l}0.2765 \\
(17.38)\end{array}$ & $\begin{array}{c}0.0001239 \\
(23.87)\end{array}$ & $\begin{array}{l}0.1550 \\
(21.58)\end{array}$ & $\begin{array}{l}0.8218 \\
(189.8)\end{array}$ & - & $\begin{array}{l}0.0463 \\
(4.772)\end{array}$ & 4722 & -9432 & -9394 \\
\hline $\begin{array}{c}\mathrm{AR}(1,1)-\mathrm{GARCH}( \\
1,1)-\mathrm{t} \\
\mathrm{DoF}=4.1042\end{array}$ & $\begin{array}{c}0.009313 \\
(13.83)\end{array}$ & $\begin{array}{l}0.3035 \\
(20.63)\end{array}$ & $\begin{array}{r}6.993 \mathrm{e}-05 \\
(6.1481)\end{array}$ & $\begin{array}{l}0.1818 \\
(11.77)\end{array}$ & $\begin{array}{l}0.8181 \\
(74.02)\end{array}$ & - & - & 5169 & -10327 & -10289 \\
\hline $\begin{array}{c}\text { AR(1,1)-EGARCH } \\
(1,1)-\mathrm{t} \\
\text { DoF }=3.4241\end{array}$ & $\begin{array}{c}0.009316 \\
(14.66)\end{array}$ & $\begin{array}{l}0.2996 \\
(21.01)\end{array}$ & $\begin{array}{l}-0.05507 \\
(-3.952)\end{array}$ & $\begin{array}{l}0.3116 \\
(14.54)\end{array}$ & $\begin{array}{l}0.9892 \\
(389.0)\end{array}$ & $\frac{-0.008343}{(-0.7444)}$ & - & 5181 & -10347 & -10303 \\
\hline $\begin{array}{c}\mathrm{AR}(1,1)-\mathrm{GJR}(1,1)- \\
\mathrm{t} \\
\mathrm{DoF}=4.1122\end{array}$ & $\begin{array}{c}0.009247 \\
(13.56)\end{array}$ & $\begin{array}{l}0.3037 \\
(20.62)\end{array}$ & $\begin{array}{l}7.115 \mathrm{e}-05 \\
(6.189)\end{array}$ & $\begin{array}{l}0.1661 \\
(9.288)\end{array}$ & $\begin{array}{l}0.8167 \\
(73.54)\end{array}$ & - & $\frac{0.03425}{(1.608)}$ & 5171 & -10327 & -10283 \\
\hline
\end{tabular}

Table 4. Test result of parameter estimation of GARCH model

Note. The numbers in the figure are parameter estimators; the numbers in parenthesis are their $\mathrm{t}$ statistics; numbers with underline mean that the parameters are not significant at 5\% significant level DoF refers to the degree of freedom of $\mathrm{t}$ distribution, and from the table 4 we can know that the all DoF tests are significant at the 5\% significant level.

It can be seen from the results of parameter estimation in table 4 that: (a) the estimation results for the parameter $\rho$ of AR (1) are significant at 5\% significant level, indicating that the AR (1) process assumption of the conditional mean $\mu_{t}$ is reasonable; (b) the degree of freedom test based on $t$ distribution is significant, indicating that the yield sequence has characteristic of fat tails distribution; (c) the estimation of GARCH coefficients $\beta_{1}$ is significant in each model, indicating that the volatility of the preceding period significantly affects the volatility of this period, and the volatility 
has obvious aggregation effect; (d) the coefficients of the model are significant in most cases, indicating that the fitting effect of the model is good; (e) the coefficients of the leverage effect are significant under the normal distribution hypothesis whereas under the hypothesis of $t$ distribution, only the coefficient of EGARCH model is significant. The results above show that the bond market has leverage effect.

\subsection{Estimation and Backtesting of VaR}

\subsubsection{VaR Estimation and Backtesting Display}

We can derive the conditional variance $\sigma_{t}$ from the GARCH model, and then different GARCH-VaR estimators can be obtained based on the VaR formula in 3.2. Taking GARCH $(1,1)-\mathrm{N}$ as an example, using the current price $P_{t}$, confidence level $\alpha$, and conditional variance estimate $\hat{\sigma}_{t}^{2}$, we can calculate the estimated value of the maximum loss of assets with a holding period of 1 days. Because the logarithmic yield in this paper is magnified 100 times, the price loss correspondingly enlarges 100 times. The VaR estimate is shown in Figure 4.

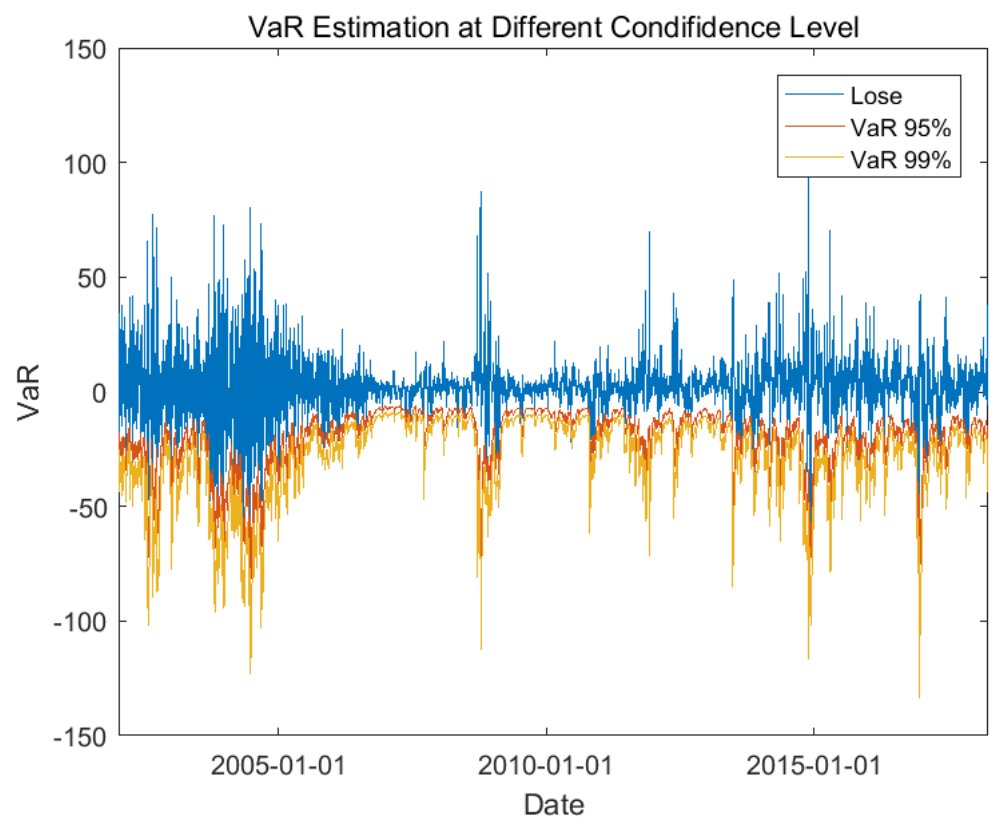

Figure 4. VaR estimation under different confidence levels based on GARCH $(1,1)$

For a vivid visual representation of GARCH-VaR and backtesting test results, we compare the VaR value of the first 100 days with the actual loss. As shown in Figure 5, under the confidence level of 99\%, the estimation of VaR is more conservative, so the number of failure is less. 


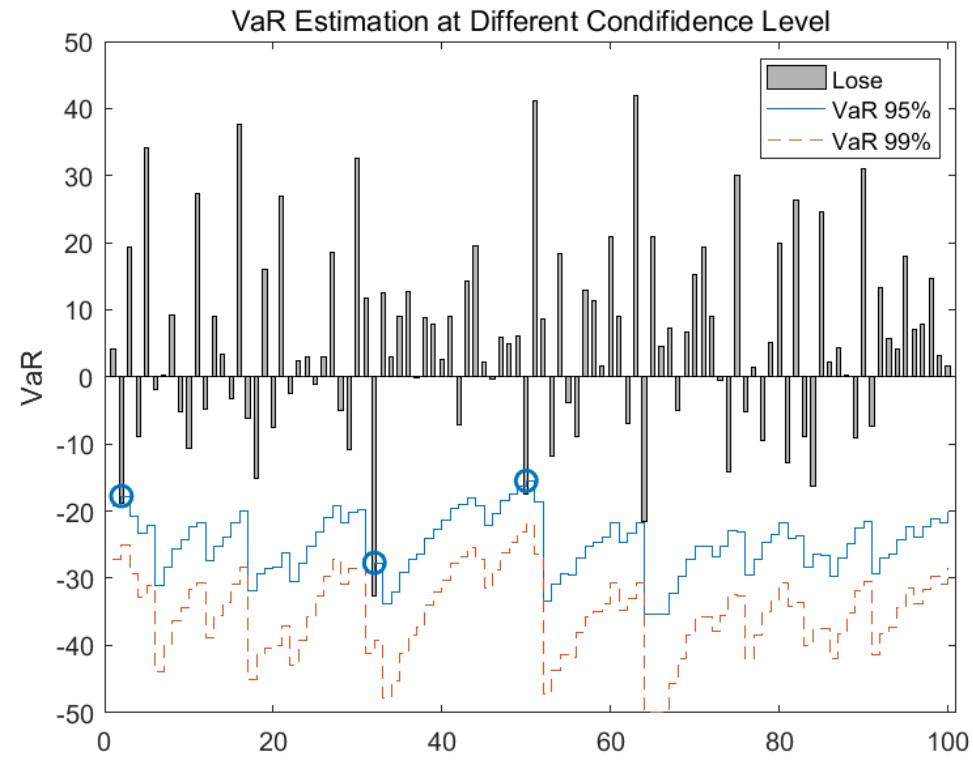

Figure 5. The effect of Backtesting

\subsubsection{Backtesting Based on Kupiec Failure Frequency Test}

We carry out Kupiec failure frequency test on VaR results estimated by different GARCH models. The test results are shown in Table 5.

Table 5. Kupiec failure frequency test results of different GARCH models

\begin{tabular}{|c|c|c|c|c|c|c|}
\hline \multirow[t]{2}{*}{ model } & \multicolumn{3}{|c|}{$95 \%$} & \multicolumn{3}{|c|}{$99 \%$} \\
\hline & $\begin{array}{c}\text { Actual } \\
\text { failure } \\
\text { rate }\end{array}$ & $\mathrm{P}(\mathrm{LR})$ & Hypothesis & $\begin{array}{c}\text { Actual } \\
\text { failure } \\
\text { rate }\end{array}$ & $\mathrm{P}(\mathrm{LR})$ & Hypothesis \\
\hline GARCH(1,1)-N & $3.52 \%$ & 0.0000 & 1 & $1.28 \%$ & 0.0860 & 0 \\
\hline $\operatorname{EGARCH}(1,1)-\mathrm{N}$ & $3.22 \%$ & 0.0000 & 1 & $1.11 \%$ & 0.4992 & 0 \\
\hline $\operatorname{GJR}(1,1)-\mathrm{N}$ & $3.49 \%$ & 0.0000 & 1 & $1.28 \%$ & 0.0860 & 0 \\
\hline $\begin{array}{l}\mathrm{GARCH}(1,1)-\mathrm{t} \\
\mathrm{DoF}=4.7351\end{array}$ & $1.97 \%$ & 0.0000 & 1 & $0.39 \%$ & 0.0001 & 1 \\
\hline $\begin{array}{c}\text { EGARCH(1,1)-t } \\
\text { DoF }=4.1423\end{array}$ & $1.57 \%$ & 0.0007 & 1 & $0.30 \%$ & 0.0000 & 1 \\
\hline $\begin{array}{c}\mathrm{GJR}(1,1)-\mathrm{t} \\
\mathrm{DoF}=4.8045\end{array}$ & $2.44 \%$ & 0.0000 & 1 & $0.49 \%$ & 0.0003 & 1 \\
\hline $\mathrm{AR}(1)-\mathrm{GARCH}(1,1)-\mathrm{N}$ & $3.59 \%$ & 0.0000 & 1 & $1.43 \%$ & 0.0000 & 1 \\
\hline AR(1)-EGARCH(1,1)-N & $3.37 \%$ & 0.0000 & 1 & $1.28 \%$ & 0.0860 & 0 \\
\hline $\operatorname{AR}(1)-G J R(1,1)-N$ & $3.49 \%$ & 0.0000 & 1 & $1.40 \%$ & 0.0150 & 0 \\
\hline $\begin{array}{c}\mathrm{AR}(1)-\mathrm{GARCH}(1,1)-\mathrm{t} \\
\mathrm{DoF}=4.1042\end{array}$ & $2.31 \%$ & 0.0000 & 1 & $0.42 \%$ & 0.0000 & 1 \\
\hline $\begin{array}{c}\mathrm{AR}(1)-\mathrm{EGARCH}(1,1)-\mathrm{t} \\
\mathrm{DoF}=3.4241\end{array}$ & $1.28 \%$ & 0.0860 & 0 & $0.17 \%$ & 0.0000 & 1 \\
\hline $\begin{array}{l}\mathrm{AR}(1)-\mathrm{GJR}(1,1)-\mathrm{t} \\
\mathrm{DoF}=4.1122\end{array}$ & $2.29 \%$ & 0.0000 & 1 & $0.37 \%$ & 0.0000 & 1 \\
\hline
\end{tabular}

Note 1 : indicates the rejection of null hypothesis, 0 means the acceptance of null hypothesis, so when hypothesis in the above table equals 0 , the model is more robust.

From the results of Kupiec failure rate test, we can see that most of the models reject the null hypothesis, but the actual failure rate is less than $3.59 \%$ under different confidence levels, indicating a good estimation effect. From the principle of Kupiec failure rate test we can derive that the estimators of most of the GARCH-VaR models built in this paper are conservative, and the number of failures is so small that LR is too big. Thus, the null hypothesis of Kupiec failure rate test is rejected. 
More specifically: (a) most of the VaR estimation models under normal distribution hypothesis are able to pass the Kupiec test, and the models are more robust. However, the VaR estimation model under the t distribution hypothesis has lower failure rate, which indicates that $t$ distribution can better reflect the extreme situation of the market, and that its conditional variance is greater and the estimation is more conservative; (b) when we compare the situation where conditional mean equals 0 with the corresponding AR (1) model, the actual failure rate is not very different from that of the Kupiec test. However, the estimation of AR (1) model is more conservative, which can be derived from the P value of LR; (c) when the leverage term is added into the model, the actual failure rate becomes lower, the model more robust, and VaR's estimation more conservative.

\subsection{Filtered Historical Simulation Based on Bootstrap}

\subsubsection{Standardization and Autocorrelation Test}

After the estimation equation of GARCH, the residual sequence can be obtained. Because the FHS theory requires the residual sequence to obey the independent identical distribution (i.i.d.), plus many studies showed that the normalized residual of the yield sequence is subordinate to i.i.d., we standardize the residual sequence. We select the more robust AR (1) -EGARCH $(1,1)-\mathrm{N}$ as the research object and find that there is a certain autocorrelation in the normalized residual sequence. In order to eliminate the autocorrelation, the AR (5) -EGARCH $(1,1)-\mathrm{N}$ model is established in this paper. The autocorrelation tests of residual and residual squared are shown in Figure 6 . The standardized residual can be approximated as the absence of autocorrelation.
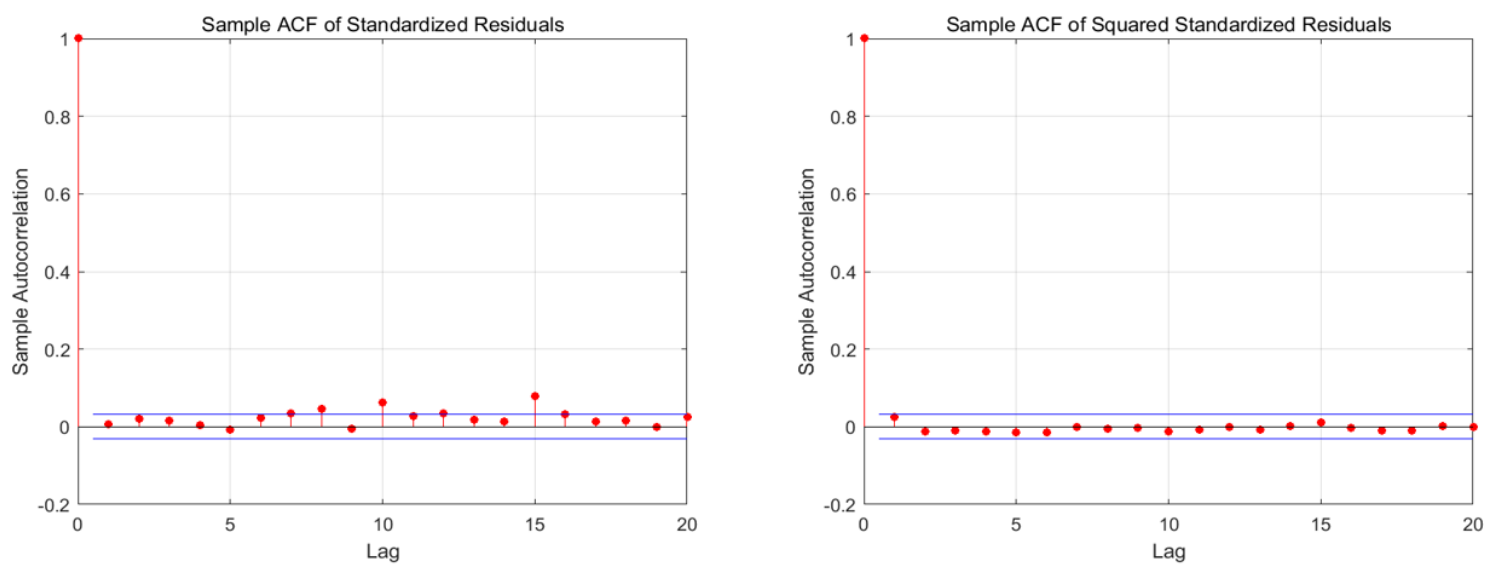

Figure 6. Autocorrelation tests of residual and residual squared

At the same time, the effect of eliminating autocorrelation or not on VaR estimation is also examined. As shown in Table 6, elimination of autocorrelation makes the actual failure rate of VaR estimation lower and the model more robust.

Table 6. The effect of autocorrelation on VaR estimation

\begin{tabular}{|c|c|c|c|c|c|c|}
\hline \multirow[t]{2}{*}{ Model } & \multicolumn{3}{|c|}{$95 \%$} & \multicolumn{3}{|c|}{$99 \%$} \\
\hline & Actual failure rate & $\mathrm{P}(\mathrm{LR})$ & Hypothesis & Actual failure rate & $\mathrm{P}(\mathrm{LR})$ & Hypothesis \\
\hline AR(1)-EGARCH(1,1)-N & $3.37 \%$ & 0.0000 & 1 & $1.28 \%$ & 0.0860 & 0 \\
\hline AR(5)-EGARCH(1,1)-N & $3.35 \%$ & 0.000 & 1 & $1.25 \%$ & 0.1162 & 0 \\
\hline
\end{tabular}

\subsubsection{FHS}

Using the normalized residual sequence, under the same initial condition, we simulate the future revenue path by Bootstrap method. The holding time of the assets is one month, that is, 20 trading days. We stimulate 20000 times a day. Then the cumulative distribution function (CDF) and the probability density function (PDF) can be obtained, as shown in Figure 7. 

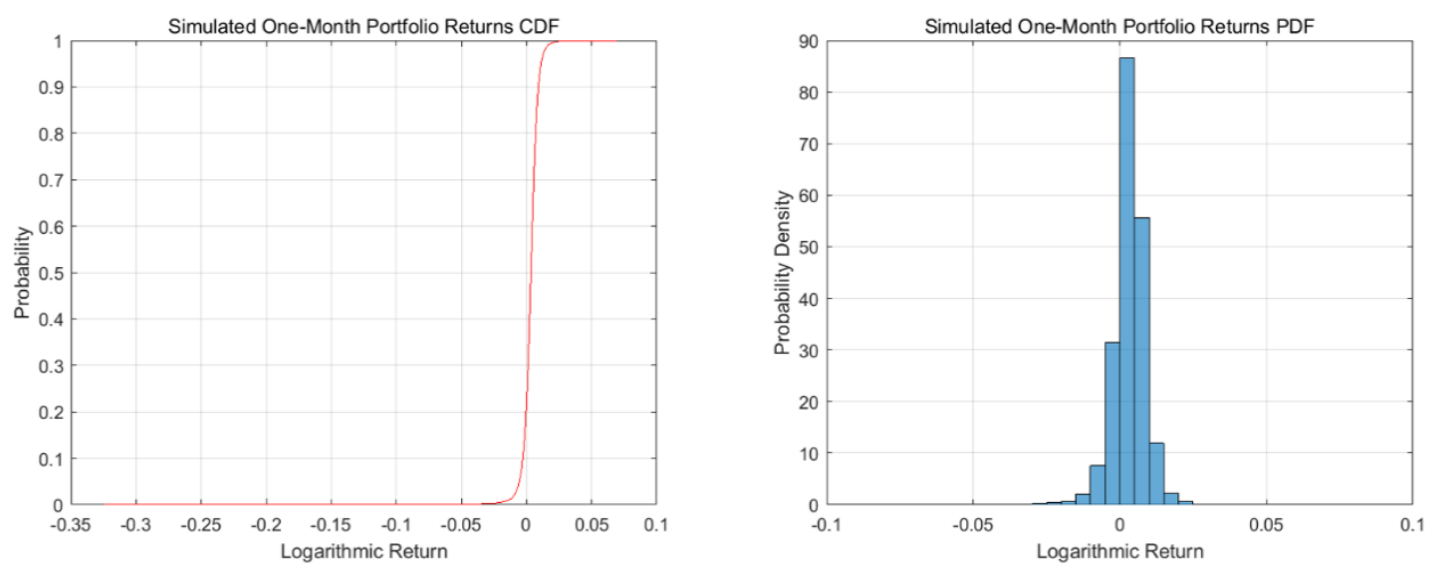

Figure 7. CDF and PDF of yield rate

As shown in Table 7, we can find, through the simulated yield outcome, that the maximum loss in the following month is as high as $27 \%$ and the maximum income is no more than $7 \%$. It shows that the market losses caused by extreme circumstances are huge, but the maximum income is not as big as the loss, indicating that the leverage effect does exist in the market. In addition, according to the VaR estimate of confidence level of $95 \%$ and $99 \%$, we can know that the market loss under normal condition is no more than $-1.4 \%$.

Table 7. simulated outcome of FHS

\begin{tabular}{|c|c|c|c|c|c|c|}
\hline & $\begin{array}{l}\text { Maximum } \\
\text { loss }\end{array}$ & possible & $\begin{array}{l}\text { Maximum } \\
\text { revenue }\end{array}$ & possible & $95 \% \mathrm{VaR}$ & $99 \% \mathrm{VaR}$ \\
\hline Loss percent & $26.6359 \%$ & & $6.8927 \%$ & & $-0.5041 \%$ & $-1.3340 \%$ \\
\hline
\end{tabular}

In order to test the simulation effect of FHS, this paper simulates the yield rate of asset holding period of 5 days, 10 days, 15 days, 20 days, and compares them with the future actual loss (April 2018). The results are shown in Table 8.

Table 8. The effect of FHS

\begin{tabular}{ccccc}
\hline & 5 days & 10 days & 15 days & 20 days \\
\hline $95 \%$ VaR & $-0.1940 \%$ & $-0.3318 \%$ & $-0.4298 \%$ & $-0.5041 \%$ \\
$99 \%$ VaR & $-0.3962 \%$ & $-0.7355 \%$ & $-0.9951 \%$ & $-1.3340 \%$ \\
Actual loss & $0.4267 \%$ & $0.2630 \%$ & $0.5657 \%$ & $-0.0830 \%$ \\
\hline
\end{tabular}

As time goes on, the VaR estimation value simulated by FHS is also magnified. But at 95\% confidence level, the estimated value can cover the actual loss, indicating that FHS has a good risk-prediction ability.

\section{Conclusions and Suggestions}

Accurately measuring the risk of bond market is very important for improving the risk management level of the bond market and maintaining the stability of the financial system. Taking ChinaBond New Composite Wealth (gross) Index as the research object, this paper constructs different bond market yield volatility models, uses VaR to measure the risk of the bond market in China, and compares the measurement accuracy of various models through the backtesting analysis and the Kupiec failure rate test method. Then, this paper uses the Filtered Historical Simulation method based on Bootstrap method to simulate VaR with different confidence levels and the maximum possible loss and revenue of the market under extreme conditions. At the same time, by comparing with the actual loss, the risk prediction ability of FHS is measured. The results of the study show that:

(1) The yield rate of the bond market has the characteristic of thick tails. The actual failure rate of the GARCH-VaR model based on $t$ distribution is lower, and such model can measure the risk of the market more accurately. But, under the Kupiec test, the robustness of the model is not as good as the one which is based on normal distribution hypothesis;

(2) The yield rate of the bond market not only has volatility aggregation effect, but also has leverage effect. The leverage term provides more effective information in the market, which can improve the estimation accuracy and robustness of $\mathrm{VaR}$;

(3) The yield rate of the bond market has a certain autocorrelation. Eliminating the autocorrelation of yield can effectively improve the estimation accuracy and robustness of VaR;

(4) Filtered Historical Simulation method based on Bootstrap method reflects the existence of leverage effect in the market, that is, the maximum possible loss of the market is far greater than the maximum possible revenue in the 
coming period. Using FHS to estimate the risk can effectively measure the actual loss of the market.

The above conclusions have important guiding significance in the risk management practice of the bond market. As we know, outbreaks of extreme risks tend to destroy the smooth operation of the market and bring great losses to investors. Therefore, preventing and resolving extreme risks is of great significance to the development of the bond market and the safety of investment. In order to prevent and resolve extreme market risks, we must focus on the typical characteristics of extreme risk measurement, such as fat tail distribution, volatility aggregation and leverage effect, which have high application value. According to these characteristics and changes, the regulatory authorities can choose appropriate models to describe the risk of the bond market and formulate corresponding risk management measures; investors can also choose the appropriate model to measure risk and specify their own investment strategies by taking their own risk tolerance into consideration. Meanwhile, both supervisors and investors can effectively evaluate the risk of the portfolio by FHS, thus effectively avoiding huge risk.

\section{References}

Ba, S. (2000). The development of China's bond market and its impact on interest rate policy and bank risk management, Journal of Financial Research, (2), 67-72.

Bali, T. G. (2007). An extreme value approach to estimating interest-rate volatility: Pricing implications for interest-rate options, Management Science, 53(2), 323-339. https://doi.org/10.1287/mnsc.1060.0628

Barone, A., G., \& Giannopoulos, K. (2001). Non parametric VaR Techniques. Myths and Realities, Economic Notes, 2001, 30(2), 167-181. https://doi.org/10.1111/j.0391-5026.2001.00052.x

Barone, A. G., Bourgoin, F., \& Giannopoulos, K. (1998). Don’t Look Back, Risk, (8), 100-104.

Barone, A. G., Giannopoulos, K., \& Vosper, L. (2002). Backtesting Derivative Portfolios with Filtered Historical Simulation (FHS), European Financial Management, 8(1), 31-58. https://doi.org/10.1111/1468-036X.00175

Bhattacharyya, M., \& Ritolia, G. (2008). Conditional VaR using EVT-Towards a planned margin scheme, International Review of Financial Analysis, 17(2), 382-395. https://doi.org/10.1016/j.irfa.2006.08.004

Champagne, C., Coggins, F., \& Sodjahin, A. (2017). Corporate bond market interdependence: Credit spread correlation between and within U.S. and Canadian corporate bond markets, North American Journal of Economics \& Finance, 41, 1-17. https://doi.org/10.1016/j.najef.2017.03.004

Chordia, T., Roll, R., \& Subrahmanyam, A. (2003). Determinants of Daily Fluctuations in Liquidity and Trading Activity, Cuadernos De Economía, 2003, 40(121), 728-751. https://doi.org/10.4067/S0717-68212003012100046

Cochrane, J. H., \& Piazzesi, M. (2005). Bond Risk Premia, American Economic Review, 95(1), 138-160. https://doi.org/10.1257/0002828053828581

Darbha, M., \& Dufour, A. (2014). The Term Structure of Bond Market Illiquidity and Default Risk, Social Science Electronic Publishing, 2014.

Heinke, V. G. (2006). Credit spread volatility, bond ratings and the risk reduction effect of watchlistings, International Journal of Finance \& Economics, 11(4), 293-303. https://doi.org/10.1002/ijfe.275

Hou, X., Huang, D., Chen, Y., \& Xu, K. (2016). Analysis of the application value of typical facts in risk management of China's bond market, Management Review, 28(09), 41-50.

Li, Y. (2003). The credit risk of corporate bonds and the development of China's corporate bond market, Journal of Renmin University of China, (03), 111-116.

Liang, J., Zhao, Y., \& Zhang, X. (2016). Utility indifference valuation of corporate bond with credit rating migration by structure approach , Economic Modelling, 54, 339-346. https://doi.org/10.1016/j.econmod.2015.12.002

Liu, S., \& Zhao, X. (2005). China: the risk and prevention of Municipal Income Bonds, Management World, (03), 50-57.

Nitschka, T. (2018). Bond market evidence of time variation in exposures to global risk factors and the role of US monetary policy, Journal of International Money \& Finance, 83. https://doi.org/10.1016/j.jimonfin.2018.02.002

Pan, J., Xiao, Q. X., \& School, B. (2016). Pricing of Corporate Bond with Stochastic Recovery Risk under the Hybrid Model, Systems Engineering, 2016.

Pritsker, M. (2006). The hidden dangers of historical simulation, Journal of Banking \& Finance, 30(2), 561-582. https://doi.org/10.1016/j.jbankfin.2005.04.013

Schuknecht, L., Von Hagen, J., \& Wolswijk, G. (2009). Government Risk Premiums in the Bond Market: EMU and Canada, European Journal of Political Economy, 25(3), 371-384. https://doi.org/10.1016/j.ejpoleco.2009.02.004 
Siu, T. K., \& Yang, H. (2000). A P. D. E. Approach for Measuring Risk of Derivatives. Applied Mathematical Finance. 7(3), 211-228. https://doi.org/10.1080/13504860110045741

Song, M., \& Hu, P. (2018). The threshold effect of credit risk in the bond market and the choice of regulation strategies from the perspective of monetary cycle, Financial Theory \& Practice, (04), 8-13.

Sukcharoensin, P., \& Sukcharoensin, S. (2010). Applications of statistical distributions in risk management, European Journal of Economics Finance \& Administrative Sciences, (26), 65-84.

Sun, J. (2017). Research on credit risk of bond market based on securities trading information, M.A. Thesis. Harbin Institute of Technology.

Tang, T. L., \& Shieh, S. J. (2012). Long memory in stock index futures markets: A value-at-risk approach, Physica A Statistical Mechanics \& Its Applications, 366(1), 437-448. https://doi.org/10.1016/j.physa.2005.10.017

Von Hagen, J., Schuknecht, L., \& Wolswijk, G. (2010). Government bond risk premiums in the EU revisited: The impact of the financial crisis, European Journal of Political Economy, 27(1), 36-43. https://doi.org/10.1016/j.ejpoleco.2010.07.002

Wua, P. T., \& Shiehb, S. J. (2007). Value-at-Risk analysis for long-term interest rate futures: Fat-tail and long memory in return innovations, Journal of Empirical Finance, 14(2), 248-259. https://doi.org/10.1016/j.jempfin.2006.02.001

Yang, Q. (2007). Research on the credit risk control of municipal bonds in the process of Marketization, M.A. Thesis. Zhejiang University.

Zhang, R., Wang, C., Fang, Z., \& Liang, W. (2010). Influencing factors and correlation of liquidity risk in China's interbank bond market, Systems Engineering, 28(03), 1-7.

Zhang, Y., \& Lu, J. (2012). Self-discipline management in the development of China's bond market, China Finance, (17), 42-43.

Zong, J. (2017). Risk assessment and control in the bond market, Corporate Finance, (17), 66-68.

\section{Copyrights}

Copyright for this article is retained by the author(s), with first publication rights granted to the journal.

This is an open-access article distributed under the terms and conditions of the Creative Commons Attribution license which permits unrestricted use, distribution, and reproduction in any medium, provided the original work is properly cited. 